\title{
Offspring Study of Racial and Ethnic Disparities in Alzheimer's Disease: Objectives and Design
}

Jennifer J. Manly, Miguel Arce Rentería, Justina F. Avila, Indira Turney, Jet M.J. Vonk, Patrick Lao, Dominika Seblova, Judes Fleurimont, Michelle N. Martinez, \& Adam M. Brickman

Taub Institute for Research on Alzheimer's Disease and the Aging Brain, College of Physicians and Surgeons, Columbia University, New York, NY 10032, USA

Gertrude H. Sergievsky Center, College of Physicians and Surgeons, Columbia University, New York, NY 10032, USA

Department of Neurology, College of Physicians and Surgeons, Columbia University, New York, NY 10032, USA

Running Title: Offspring Study of Alzheimer's Disparities

Correspondence to: Jennifer J. Manly, Ph.D., Taub Institute for Research on Alzheimer's Disease and the Aging Brain. 630 W 168th St, P\&S Box 16, New York, NY, 10032, Tel: (212) 305-8604. Email: jjm71@cumc.columbia.edu 


\section{Abstract}

Alzheimer's Disease (AD) is a neuropathologically heterogeneous clinical syndrome, which disproportionately affects Non-Latinx Black and Latinx older adults. There are likely to be multiple mechanistic pathways to $A D$, and these pathways may be racially patterned and may account for racial/ethnic disparities in AD. Our research suggests that lifecourse social forces, such as discrimination, policy-driven investment in schooling, and early life SES are drivers of these different pathways and promote resilience or confer risk for cognitive decline. Intergenerational studies provide insight into these mechanisms so that we can inform preventive strategies and interventions to narrow disparities in cognitive decline and AD. The Offspring Study of Racial and Ethnic Disparities in Alzheimer's Disease began in 2017 to identify biological and sociocultural mechanisms of disparities in cognitive function among middle-aged people with and without a parent with AD. Partnering with the multi-ethnic, neighborhood-based Washington Heights Inwood Columbia Aging Project (WHICAP) study as the parent cohort, the Offspring study assesses neuropsychological, psychosocial, and medical function, reading level, health literacy, and bilingualism. Lifecourse social and environmental exposures are surveyed through, in part, lifetime residential, educational, and occupational histories. Participants provide blood for biomarker and genetic analysis, and structural and functional MRI neuroimaging and PET imaging of cerebral amyloid and tau pathology is conducted. This article outlines the objectives and design of this prospective cohort study aimed at advancing the understanding of risk factors among middle aged offspring in order to clarify pathways to $A D$, and provides background on recruitment and retention of this diverse cohort. 
Key Words: Alzheimer Disease, Health Status Disparities, Minority Health, Cognitive Aging, Social

Determinants of Health, Neuroimaging, Biomarkers 


\section{INTRODUCTION}

\section{Racial/Ethnic Disparities in AD}

There are racial/ethnic disparities in AD prevalence ${ }^{1-11}$ and incidence ${ }^{12,13}$; non-Latinx Black and Latinx older adults have elevated rates of clinical AD history of clinical AD (hereafter referred to as $A D$ ) compared with non-Latinx Whites ${ }^{14,15}$. These racial disparities are more consistently observed in community-based studies than in clinic-based studies ${ }^{14,16-20}$. The causal pathways of racial/ethnic disparities in risk for $A D$ dementia are not well understood. The prevalence of many cardiovascular and demographic risk factors for $A D$ is higher, and educational attainment lower, among African Americans and Latinxs than among Whites. Cardiovascular conditions such as hypertension, diabetes, insulin resistance, obesity/overweight, and hyperlipidemia ${ }^{21-29}$, as well as cerebrovascular disease including stroke, silent infarcts, and white matter hyperintensities $(\mathrm{WMH})^{30}$ have also been associated with higher risk for developing cognitive decline and AD. Educational quality and quantity are associated with $A D$ risk, independent of race $21,23,24,26,31-36$. The contribution of these factors to risk of AD may differ across racial/ethnic groups. Indeed, secular trends reveal that later birth cohorts have lower AD risk, underrepresented racial/ethnic groups have not benefitted equally ${ }^{37,38}$. There is evidence that social inequalities in early and midlife lead to vascular, inflammatory, and neurodegenerative changes, which in turn fuel disparities in cognitive aging and dementia. Studies that integrate biological, psychosocial, and clinical methods in diverse, representative cohorts are needed to understand the biopsychosocial causes of AD disparities. 


\section{$A D$ Disparities must be studied before the age of 65}

There are three primary lines of reasoning for studying $A D$ disparities before the age of 65 . First, the time from earliest pathological change to clinical AD can span over 20 years ${ }^{39,40}$. This long preclinical phase is crucial for intervention and timely diagnosis ${ }^{41}$. Second, midlife health is associated with cognitive decline and $A D$ in late life, which is particularly relevant for Black and Latinx people. Midlife vascular risk factors are associated with risk of incident dementia in all groups, ${ }^{42}$ but their impact differs by race/ethnicity. Systemic inflammation during midlife is associated with steeper memory decline ${ }^{43}$, and with white matter damage, particularly in Black people, which, in turn, is associated with AD in late life ${ }^{44,45}$. In fact, the strength of the relationship between late-onset $A D$ and hypertension, diabetes, insulin resistance, obesity/overweight, and hyperlipidemia appears to be strongest if these risks are assessed in middle age ${ }^{21,31,32,46,47}$. Black people show evidence of accelerated biological aging compared with Whites ${ }^{48-50}$. Racial/ethnic differences in biological aging widen through midlife until late-life, when this gap narrows ${ }^{50}$. Third, the mechanisms underlying late-life cognitive outcomes are difficult to study if samples are limited to old age because of bias related to differential survival ${ }^{51}$, particularly in Black and Latinx men. ${ }^{51-53}$ Prior studies with AD biomarkers have been limited by selection bias and small samples among non-White groups. ${ }^{30,31}$ 
Risk of sporadic AD increases 4-10 times with a first-degree family history of $A D^{54-56}$. Family history is related to earlier dementia onset ${ }^{57,58}$, to lower cognitive performance ${ }^{59}$, and to biofluidic and neuroimaging $A D$ biomarkers ${ }^{40,60-62}$, amyloid and tau pathology ${ }^{63}$, and cerebrovascular disease ${ }^{64-66}$. However, the mechanisms underlying AD risk through heritability of environmental and health risk factors are not well understood ${ }^{67,68}$. There is evidence that effect of family history differs across race/ethnicity, as familial risk of AD is higher among Black than White individuals ${ }^{69}$.

Several studies of middle-aged asymptomatic offspring who report a parent with $A D$ found impairments in multiple cognitive domains, including memory, visuospatial function, and language ${ }^{70,71}$, measures of brain atrophy ${ }^{72-77}$, amyloid burden in the brain $^{78}$, and brain metabolism ${ }^{79}$; however, some studies have found weak or no relationships ${ }^{80-82}$. Family history of $A D$ was usually determined by self-report alone. Biomarkers were not consistently evaluated in parents, and familial aggregation of risk factors was not determined. Only few large-scale cohort studies have prospectively-collected data of both parental and offspring generations ${ }^{70,83-85}$ and most research on increased risk of family history of AD is performed among volunteer-based, well-educated, White parents and offspring.

In addition to familial risk, secular changes in AD risk should be considered to place the effects of family history on development of $A D$ in context. Our group showed that later birth year is associated with better cognitive abilities and slower decline over time, but that these changes were attributable to increases in early childhood socioeconomic status (SES) and education ${ }^{38}$. The impact of secular trends related to education, prevalence of risk factors, medical care and lifestyle factors can be clarified by comparing parent and offspring generations. There is evidence 
that state and local investment in schooling, exposure to cognitively challenging tasks (through work or leisure activities), nutrition, economic status, and access and quality of health care may explain secular improvements in cognitive test performance among of older adults.

\section{Rationale for the Offspring Study}

Research on middle-aged offspring of well-characterized older adults with and without $A D$ is a powerful tool to identify biological pathways, early biomarkers, and genetic risk factors for AD. Intergenerational studies can identify the earliest changes in cognitive, brain, and blood biomarkers among asymptomatic children of people with $A D$, which can help inform the earliest sources of risk and be used as outcomes for interventions, or to identify people for clinical trials. As research and clinical diagnostic criteria for $A D$ evolve, there is a growing consensus that the $A D$ continuum is broader than previously thought ${ }^{86}$, including clinical and pathological heterogeneity ${ }^{87}$. Especially among Black and Latinx people, middle age is the ideal time to examine etiologies related to AD development; it is when impactful pathologies begin ${ }^{88}$ and when risk factors have the greatest predictive power ${ }^{89}$. There is evidence that there are different pathways to $A D$ and cognitive impairment in old age that are patterned by race and ethnicity. Our research suggests that lifecourse social forces, such as discrimination and early life SES, are drivers of these different pathways. An intergenerational design provides insight into these mechanisms so that we may inform interventions to narrow disparities in cognitive decline and AD. Our data suggest that transmission of risk for cognitive decline and ADRD in Whites is mediated more by traditional AD-related neurodegenerative pathways than among Black and 
Latinx people and that, conversely, inflammatory, vascular, and accelerated biological aging mechanisms may play a relatively greater role among Black and Latinx people. We are not proposing that $A D$ is a different disease by race or ethnicity, but that social forces drive differential relative contributions of biological factors to the disease process.

In the Offspring study, race/ethnicity is used as a marker of risk, not as a risk factor or proxy for genetic variation ${ }^{90,91}$. Following the multiple levels of analysis in the NIA Health Disparities Framework ${ }^{92}$, the design of the study incorporates measurement of structural racism, interpersonal experiences of discrimination, lifecourse educational and socioeconomic exposures, psychosocial function, medical conditions, and health behaviors.

The potential impact of the Offspring study is two-fold. First, integration of social forces and biological factors can lead to more rigorous standards for understanding the relationships between racially patterned risk factors and brain health. Second, data gathered in partnership with the community can inform and drive policy change to reduce disparities.

\section{STUDY DESIGN}

The procedures of this study are approved by the Institutional Review Board of Columbia University.

\section{The Parent Cohort}

The parental cohort is derived from participants in the Washington Heights/Hamilton Heights Inwood Columbia Aging Project (WHICAP) a multi-ethnic community-based, epidemiological study of aging and dementia in Northern Manhattan, NY (P01AG07232, R. 
Mayeux, PI, R01AG037212 R. Mayeux, N. Schupf, Co-PIs, and RF1AG054023 R. Mayeux, PI). The Offspring Study leverages a well-characterized parent cohort, the Washington Heights Inwood Columbia Aging Project (WHICAP9,37,93,94; XXXref), Parents were originally recruited in 1992, between 1999 and 2001, between 2009 and 2014, and beginning in 2017, ongoing recruitment maintains the current cohort at approximately 2000 older adults. Objective data from this parent generation, including incident AD diagnosis, cognitive function, cardiovascular disease, socioeconomic status, and brain imaging in a subset of participants are available for analysis. WHICAP parents are followed at approximately 24-month intervals with similar assessments at each interval. Each assessment wave includes an in-person interview of medical history, a physical and neurological exam, a neuropsychological battery, and an assessment of functional capacity. Historically, $8 \%$ of the non-demented participants develop dementia each year (93\% of those with dementia are diagnosed with AD), annual mortality has averaged approximately $10 \%$, and $80 \%$ return for follow-up at each follow-up wave. Follow-up rates do not differ by ethnicity or educational level, but mortality is highest for African American men and lowest for Latinx women. Blood for genetic and biomarker studies have been collected at multiple intervals. Since 2005, a total of 1,800 WHICAP participants have had MRI imaging (32\% White, 33\% Hispanic/Latinx, and 35\% African American); currently, 350 have undergone repeat scans. A total of 161 WHICAP participants have undergone amyloid PET imaging. About $77 \%$ of participants have at least one child.

To date, we have successfully enrolled offspring from 872 WHICAP parents; Table 1 shows characteristics of the parents whose offspring were recruited. Average age at onset of AD was 81 
years ( $23 \%$ were prevalent and $77 \%$ were incident $A D)$. Established criteria were used to diagnose parents with $\mathrm{AD}^{95}$ or $\mathrm{MCl}^{94,96,97}$

Table 1. Characteristics of WHICAP Parent of Offspring Participants

\begin{tabular}{|c|c|c|c|c|c|}
\hline & $\begin{array}{l}\text { Parents } \\
\text { with } A D\end{array}$ & $\begin{array}{c}\text { Parents } \\
\text { with } \mathrm{MCl}\end{array}$ & $\begin{array}{c}\text { Parents with } \\
\text { normal } \\
\text { cognition }\end{array}$ & $\begin{array}{l}\mathrm{X}^{2} \text { or } \mathrm{F} \\
\text { statistic }\end{array}$ & range \\
\hline $\mathrm{N}$ & 234 & 240 & 398 & & \\
\hline Age & 78.3 & 74.4 & 73.9 & $40.2^{* * *}$ & $63-103$ \\
\hline$\%$ women & $79 \%$ & $78 \%$ & $79 \%$ & 0.188 & \\
\hline Race/Ethnicity & & & & $73.1^{* * *}$ & \\
\hline Latin $x$ & $84 \%$ & $62 \%$ & $52 \%$ & & \\
\hline Non-Latinx Black & $11 \%$ & $24 \%$ & $27 \%$ & & \\
\hline Non-Latinx-White & $5 \%$ & $15 \%$ & $18 \%$ & & \\
\hline \# of children & 5.0 & 3.9 & 3.4 & $32.2 * * *$ & $1-14$ \\
\hline \# Offspring participating & 2.1 & 1.5 & 1.5 & $37.7 * * *$ & $1-10$ \\
\hline Years of school & 5.6 & 9.3 & 11.0 & $97.2 * * *$ & $0-20$ \\
\hline \% with HTN & $75 \%$ & $75 \%$ & $69 \%$ & 3.2 & \\
\hline$\%$ with diabetes & $42 \%$ & $30 \%$ & $28 \%$ & $13.1 * * *$ & \\
\hline Years of follow-up & 8.6 & 7.4 & 5.7 & $22.9 * * *$ & $0-26$ \\
\hline Dead & 33.8 & 19.2 & 19.4 & $18.5^{* * *}$ & \\
\hline
\end{tabular}

$* * * p<.001$

\section{The Offspring cohort}

Offspring are adult children of WHICAP participants, age 28 or older, fluent in English or Spanish, willing to donate a sample of blood, and willing to be followed longitudinally. To date, we have enrolled 1,469 Offspring. Table 2 displays the characteristics of Offspring at the time of the last data freeze $(n=1,384)$. While almost $98 \%$ of the people who identify as Hispanic/Latinx in the parent cohort are primarily Spanish speakers, 32\% of their offspring felt most comfortable in English. Compared to Spanish-speaking Latinx, the English-speaking Latinx were younger, had more years of school, were less likely to have a parent with $A D$, and were more likely to be assessed 
remotely. Although we originally proposed three racial/ethnic groups to be the focus in the Offspring Study, we did not take into account this major source of heterogeneity within the Latinx group.

Table 2. Offspring Cohort Characteristics

\begin{tabular}{lccccc}
\hline & $\begin{array}{c}\text { Non- } \\
\text { Latinx } \\
\text { White }\end{array}$ & $\begin{array}{c}\text { Non- } \\
\text { Latinx } \\
\text { Black }\end{array}$ & $\begin{array}{c}\text { Latinx } \\
\text { Tested in } \\
\text { English }\end{array}$ & $\begin{array}{c}\text { Latinx } \\
\text { Tested in } \\
\text { Spanish }\end{array}$ & $\begin{array}{c}\mathrm{X}^{2} \text { or F } \\
\text { statistic }\end{array}$ \\
\cline { 2 - 6 } $\mathrm{N}$ & 139 & 245 & 321 & 679 & \\
Age (mean) & 56.1 & 56.1 & 51.0 & 59.6 & $35.9^{* * *}$ \\
Gender (\% female) & 65 & 63 & 66 & 70 & 7.9 \\
Years of school (mean) & 16.7 & 13.9 & 13.9 & 10.9 & $149.9^{* * *}$ \\
APOE E4 allele present (\%) & 29.4 & 39.1 & 26.0 & 26.9 & $7.5^{*}$ \\
Parent with MCl (\%) & 31 & 30 & 24 & 25 & 4.9 \\
Parent with AD (\%) & 7 & 16 & 22 & 49 & $168.3^{* * *}$ \\
Parent yrs of school (mean) & 14.6 & 12.9 & 8.2 & 5.6 & $360.6^{* * *}$ \\
Parent with HTN (\%) & 42 & 75 & 76 & 78 & $74.4^{* * *}$ \\
Parent with diabetes (\%) & 6 & 28 & 40 & 42 & $72.9^{* * *}$ \\
Assessed remotely (\%) & 50 & 21 & 25 & 10 & $49.4^{* * *}$ \\
\hline
\end{tabular}

Characteristics of Offspring MRI subsample. All participants are offered participation in the MRI aspect of the study. To date, we have successfully scanned $38 \%$ of the cohort $(n=549)$. MRI participants were a random subset of the overall study cohort, with the goal of scanning one participant per family. Approximately $18 \%$ approached about MRI scanning indicated that they were not interested. Of those indicating interest, $12 \%$ were deemed ineligible based on initial screening. Of the participants who indicated that they were eligible and passed initial screening, we successfully scanned $84 \%$. Compared with individuals who were not approached and not scanned, those who received MRI scans were younger $(54.5 \pm 10.7$ vs. $57.8 \pm 11.7, t=5.26, p<0.001)$, had a higher proportion of Black participants ( $21 \%$ vs. $14 \%$ ) and lower proportion of White 
participants ( $6 \%$ vs. $\left.12 \% ; \chi^{2}=30.1, p<0.001\right)$, but were similar in sex/gender distribution $\left(\chi^{2}=2.95\right.$, $p=0.23)$.

\section{PROCEDURES}

\section{The Offspring Study Team}

The majority of the staff is bilingual (English-Spanish) and bicultural (e.g., DominicanAmerican), and were born and raised in the area. We require prospective research assistants to undergo two to three weeks of training and certification to demonstrate their language fluency, abilities in the interview setting, and facility with standard procedures. During these weeks of training, a bilingual/bicultural neuropsychology postdoctoral fellow (MAR), under the supervision of senior neuropsychologists (JJM/AMB), assisted in training and supervision of standardized administration of the neuropsychological battery. Similarly, all staff members complete thorough training and certification on the administration of the medical evaluation and sociocultural questionnaires under the supervision of the study coordinator (MNM).

\section{Recruitment}

Offspring who agree to be seen for the study are scheduled for an in-person visit in their home or in an office on the campus of Columbia University Irving Medical Center to obtain informed consent and to determine whether inclusion/exclusion criteria are met. Participants are paid for their participation and costs incurred from travel to the testing site are reimbursed. 


\section{Language of Administration}

Language of test administration is assessed at scheduling but can be modified once the participant is observed by a bilingual examiner. First, participants are contacted by an EnglishSpanish bilingual staff member to determine interest in participating in the study and for scheduling. Before administration of measures, our interviewers describe the cognitive testing and survey activities in general terms, and ask the participants to decide which language they would feel most comfortable using for the evaluation. This choice determines the language used for follow-up evaluations as well.

\section{Community Engagement and Social Work Services}

We encounter high levels of unmet medical, social, psychological, and financial needs among our participant population and their families. Emergent medical and psychosocial conditions are rarely encountered during the parent WHICAP study. It has been rare for WHICAP participants to have conditions such as dangerously high blood pressure and suicidality requiring emergency psychiatric care, to request help for dealing with domestic abuse or substance dependence, or to have difficulty scheduling visits due to recent loss of jobs or homelessness. Yet these examples are daily occurrences in the Offspring study. WHICAP parents are all covered by Medicare - in fact, they were recruited via CMS lists of Medicare beneficiaries. In contrast, many of their middle-age children have no medical insurance and are reluctant to seek medical followup when necessary because of concerns of financial burden; this situation has been further exacerbated by the COVID-19 pandemic. 
To improve research engagement, and following the example of Dr. Lisa Barnes in the MARS Study at Rush University Medical Center ${ }^{98}$, we successfully engaged bilingual staff with social work expertise in the Washington Heights community who provides culturally-tailored assessment and links to services among our participants, and developed culturally tailored family-based health education and outreach activities. Engagement of the offspring generation in research requires additional assessment of individual needs, experience with assigning levels of care and linkages for services, and consistent follow-up to ensure that participants are connected with culturally and linguistically appropriate social and medical services The provision of culturally tailored information and support for basic life needs demonstrates reciprocal gain from participation in the study among WHICAP families, increasing research engagement among WHICAP families, increasing recruitment of all offspring within a family, and aiding retention over time.

The social worker has the opportunity to meet with every participant during or after their evaluation and makes house calls if needed. The social worker assesses the needs of each participant and assigns levels of care and determine linkages for services, ensuring that every participant is connected with appropriate services that are responsive to their financial and health insurance status. These encounters and connection to services are documented, tracked, and coded. The social worker has also tailored informational materials for our research staff, including social services and COVID-19 specific services guides, and collaborate with the recruitment specialist to design community engagement activities. Social work engagement enriches the participatory experience, leading to stronger community engagement and partnership. Ultimately, the effort improves recruitment and retention, maximizes the quality 
and fidelity of the data collected, and leads to greater trust and partnership between the investigators and community.

\section{Measures}

\section{Race and ethnicity}

Race and ethnicity are self-identified, using methods identical to the according to the Precision Medicine Initiative All of Us Research Program (PMI-AURP; Precision Medicine Initiative Working Group Report ${ }^{99}$. Participants self-identify racial and ethnic categories that apply to them (i.e., American Indian or Alaskan Native, Asian, Black or African American or African, Hispanic/Latino or Spanish, Middle Eastern or North African, Native Hawaiian or other Pacific Islander, and White). Participants will also select from any subgroup within each of the race/ethnic identification above (e.g., South African, Costa Rican, Jamaican, Mexican, Senegalese).

\section{Sex and Gender}

Information on sex (e.g., male, female, intersex/other) and gender (e.g., man, woman, transman, transwoman, genderqueer/gender non-conforming, different, identified as: [specify]) are also collected.

\section{Educational Experience}

The following variables are assessed separately for elementary, high school, and post-high school phases of education: years completed, age or date of first year attended, location, name of school, setting (public vs. private), class size, and estimated ethnic composition of student body and teachers. Participants are asked whether they were ever "left back or had to repeat a grade", and whether they completed a GED. For those born in the US, information on per pupil 
expenditures, teacher salaries, pupil/teacher ratios, and length of school year have been obtained ${ }^{100-106}$ by state, and where available by county, city, and district.

\section{Family history}

Family History has already been collected from the parent cohort, but we extend and enrich the information in offspring. The structured interview ${ }^{107}$ queries about family structure, birth order, vital status, education, history of cognitive impairment, dementia, and other medical, neurologic and psychiatric disorders among first-degree relatives.

\section{Lifetime Socioeconomic Status}

Measures of childhood SES include: maternal and paternal education and occupation, childhood financial hardship, subjective childhood SES ${ }^{108}$, and number of siblings (this information is collected directly from both parents and children). Current SES is determined via collection of income, assets, debts, and material hardship ${ }^{109}$ data. Occupational history. We collect information about longest-held job: job title, duties, and start and end year, and industry type. These data are used to determine a Standard Occupation Code ${ }^{110}$, which is linked to U.S. Department of Labor Occupational Information Network $\left(O^{*} N E T\right)^{111}$, which can be used to derive indices of job characteristics such as substantive complexity and interpersonal communication.

\section{Residential History}

The location (city, state) of all the places lived for at least 1 year and ages at each move from birth to study enrollment are recorded. Current residential address is documented and verified over the follow-up period, geocoded to latitude and longitude, and then can be assigned to census tracts or linked to databases with neighborhood level SES indicators like the Area Deprivation Index ${ }^{112}$. 


\section{Social Network Size and Social Support}

Current social situation (e.g., marital/partner status, with whom the participant resides) is collected. Participants are asked how many children, friends, and other relatives they talk to at least once a month ${ }^{113}$. Total network size will be calculated by summing these items ${ }^{114}$. Social Support. Emotional and Instrumental Social support will be measured using the Social Provisions Scale ${ }^{115}$, the 3-item UCLA Loneliness Scale ${ }^{116}$, and the Social Support Scale from the NIH Toolbox Emotion Battery.

\section{Positive and Negative Psychosocial Factors}

Depressive symptoms in the past week are assessed with the CES-D ${ }^{117}$. The DSM 5 Cross-Cutting Symptom measure ${ }^{118,119}$ is used to measure symptoms of depression, anger, mania, anxiety, somatic symptoms, sleep disturbance, psychosis, obsessive thoughts/behaviors, suicidality, and substance use. Life satisfaction ${ }^{120}$, positive well-being ${ }^{121}$, self-esteem ${ }^{122}$, and perceived control ${ }^{123}$ are assessed.

\section{Experiences of Discrimination and Vigilance}

Everyday discrimination is assessed with a modified version of the Everyday Discrimination Scale ${ }^{124,125}$. This 10 -item scale asks participants about experiences of general interpersonal mistreatment such as "You are treated with less respect than other people" and "You are treated as if you are not smart" over the course of the last 12 months. Responses to each item are rated on a 1 to 4 scale $(1=$ never, $2=$ rarely, $3=$ sometimes, $4=$ often $)$. Each item/example of mistreatment does not refer to race/ethnicity, gender, or other individual characteristics and thus has been validated for use among participants of many ethnic and educational backgrounds ${ }^{126-129}$ and has excellent internal consistency and convergent and divergent validity ${ }^{126,130}$. 
Major experiences of discrimination are determined by asking about perceived discrimination and experiences of violations of civil rights ${ }^{124}$. This 9-item scale includes items such as "Do you think you have ever been unfairly fired or denied a promotion?" and "Have you ever been unfairly discouraged by a teacher or advisor from continuing your education?" Participants are asked when the last time each event happened $(1=$ within the last week, $2=$ within the last month, 3 = within the last year, 4 = more than a year ago), and how many time each event happened in their lifetime. Finally, the perceived reason for this experience is assessed $(1=$ ancestry/national origins, $2=$ gender, $3=$ race, $4=$ age, $5=$ height $/$ weight, $6=$ skin color, $7=$ other). The Vigilant Anticipatory Coping measure ${ }^{131}$ assesses racism-related vigilance.

\section{Stress and Lifetime Trauma}

The Perceived Stress measure from the NIH Toolbox is administered. Participants are asked whether they experienced any of 12 potentially adverse events before the age of $18^{114}$. We added a COVID-19 questionnaire in May 2020 that examines health, financial, housing, and psychosocial events that participants may be facing due to the pandemic.

\section{Bilingualism}

The Offspring study presents a unique cohort to characterize bilingualism and investigate it associations to cognition and neuroanatomical structures. The parental cohort are primarily immigrants and generally reside within the Washington Heights and Inwood neighborhoods within Northern Manhattan. These neighborhoods are rich in bilingual experiences due to multigenerational homes, and the community businesses and services are available in both English and Spanish. Bilingualism is assessed with both self-report and objective measures. Self-reported bilingualism is obtained through a Language History Questionnaire (LHQ). The LHQ represents a 
modified and expanded version of the Bilingual Language Profile (BLP). The Offspring LHQ measures language history (i.e., age of exposure and acquisition, number of exposed languages, method of acquisition), language use (i.e., frequency of use across different contexts, language dominance), language proficiency (i.e., reading, writing, speaking, understanding), frequency of code-switching, and language attitudes (i.e., "it is important to me to use English like a native speaker", "it bothers me when speakers mix languages"). The Offspring LHQ is available in both English and Spanish and allows for endorsing more than 2 languages (i.e., multilingualism). A subsample of the participants is administered the 68-item Multilingual Naming Test (MINT; Gollan et al., 2012), a well-validated objective measure of bilingualism. The administration of the extended MINT consists of presenting the participant with the items ( 6 per page) and asking them to name as many as possible in their dominant language, and then in their non-dominant language. Through the extended MINT one can compute bilingualism indices (i.e., degree of bilingualism, language dominance), correlates strongly with self-report and language surveys (Gollan et al., 2012), and is only administered to participants that identify as Latinx in both English and Spanish.

\section{Neuropsychological Examination}

Offspring participants undergo an extensive neuropsychological evaluation as part of their study visit. The neuropsychological battery is comprised of elements from three standardized and validated batteries: the WHICAP neuropsychological battery (Stern, 1992; Siedlecki 2010), the University of Washington's National Alzheimer's Coordinating Center battery (NACC; Weintraub 2018), and the NIH Toolbox (NIHTB; Gershon et al., 2013; Weintraub, et al., 2013). These three batteries were combined in order to compliment domains already being assessed in the WHICAP 
study (i.e., memory, language, visuospatial functioning) and provide a more comprehensive assessment of other cognitive domains (executive functioning) as well as an assessment of motor and sensation functioning.

The WHICAP neuropsychological test battery has been validated (Stern et al., 92), administered over 16,000 times in Spanish and English since 1992, and used in hundreds of analyses and publications. This battery continues to be administered to parents at each assessment wave. The NACC neuropsychological battery was developed as part of the of Uniform Data Set (UDS) data collection protocols used across NIA-Alzheimer's Disease Centers (ADC) designed to differentiate between normal cognition, mild cognitive impairment $(\mathrm{MCl})$, and dementia among adults over the age of 60 , and has undergone three revisions (Weintraub et al., 2018). The NIH Toolbox was developed with a similar goal to collect information on aspects of neurologic and behavioral function in a uniformed manner among individuals spanning the age range from 3 to 85 years (Gershon et al., 2013). The WHICAP, NACC, and NIH Toolbox batteries have been translated and validated for use among Spanish-speakers ${ }^{132-134}$.

The cognitive battery includes measures of learning and memory (the Selective Reminding Test ${ }^{135}$, Craft Story Memory ${ }^{136}$, and Benson Complex Figure Delayed Recall ${ }^{137}$ ), visuospatial ability (Benson Complex Figure Copy ${ }^{137}$ ) language (Multilingual Naming Test ${ }^{138}$, Controlled Oral Word Association Test ${ }^{139}$, Category Fluency Test ${ }^{140}$, NIH Toolbox Vocabulary), psychomotor speed (Color Trails Test, Part $1^{141}$, WAIS-R Digit Symbol subtest ${ }^{142}$, and NIH Toolbox Pattern Comparison ${ }^{143}$ ) and executive functioning (NIH Toolbox Flanker and Dimensional Change Card Sort ${ }^{143}$, Color Trails 2). English and Spanish reading level is assessed using the NIH Toolbox Oral Reading Recognition Test ${ }^{144}$, the WRAT-IV ${ }^{145}$, and the Word Accentuation Test ${ }^{146,147}$. Table X 
lists each of the neuropsychological tests by cognitive domain. The Color Trails Test was selected instead of the Trail Making Test (TMT) because it is more appropriate for this population, many of whom do not have enough knowledge of the alphabet for satisfactory completion of TMT Trial $\mathrm{B}^{141,148}$. Additionally, we have included an additional letter to the verbal fluency tasks in order to match the measure given in the WHICAP study (i.e., from $\mathrm{F} / \mathrm{L}$ only to $\mathrm{C} / \mathrm{F} / \mathrm{L}$ ). Lastly, we have included the 12-item Brief Smell Identification Test ${ }^{149}$ which was developed as an abridged test of olfaction and validated across cross-cultural settings.

\section{Medical history interview and physiological and anthropometric measures}

The medical/neurological examination records current weight, height, visual acuity with and without glasses, hearing impairment with and without a hearing aid, and systolic and diastolic BP. Extrapyramidal signs are rated ${ }^{150-152}$. Reproductive history is recorded for women and men. Current medications, vitamin, and nutritional supplement use are queried. Presence of physiciandiagnosed conditions, such as hypertension, diabetes, elevated cholesterol, cancer, myocardial infarction (MI) or angina, other heart disease, stroke, transient ischemic attack (TIA), migraine, arthritis, thyroid disorder, osteoporosis, chronic obstructive pulmonary disease (COPD), seizure, HIV infection, head injury with loss of consciousness, depression, anxiety, neurological illness including Parkinson's disease and AD is queried. We use WHO diagnostic criteria for stroke ${ }^{153}$ and collect information on individual symptoms of stroke and TIA. History of head injury, smoking, alcohol abuse, and use of anti-inflammatory drugs is queried. For each condition named, we ascertain age at onset, duration, treatment history and whether there has been any change in the last 12 months. Self-reported sleep quality is recorded using the Pittsburgh Sleep Questionnaire ${ }^{154}$. 


\section{Depression and neuropsychiatric status}

Depressive symptoms in the past week are assessed using the 30-item Center for Epidemiologic Studies Depression (CES-D) scale ${ }^{155}$. Neuropsychiatric status was measured with the self- and informant-based DSM 5 Cross-Cutting Psychiatric Symptom Measures ${ }^{118,119}$. The Cross-Cutting Measures, which can be administered online, have been demonstrated to be a valid, reliable, brief, adaptive instrument designed to assess all major domains of psychopathology with good psychometric properties ${ }^{119}$.

\section{Daily Function and Subjective Cognitive Complaints}

The Disability and Functional Limitation Instrument is ${ }^{156,157}$ and contains self- and observer ratings in instrumental activities, personal self-maintenance activities, perceived difficulty with memory, mobility, and activities and social participation ${ }^{158}$. The Clinical Dementia Rating ${ }^{159,160}$ score is used to rate impairment caused by cognitive dysfunction. Participants are administered 3 different questionnaires that measured subjective cognitive complaint (SCC): (1) the self-report version of the Everyday Cognition (E-Cog) scale 161,162 , which contains 6 domainspecific factors that include Everyday Memory, Language, Visuospatial Abilities, Planning, Organization, and Divided Attention; (2) the Memory Functioning Questionnaire ${ }^{163}$ (MFQ), which is divided into several subscales that include the General Frequency of Forgetting, Seriousness of Forgetting, Retrospective Functioning, and Mnemonics Usage; and (3) participants were administered a set of 7 questions that were adapted from the Structured Telephone Interview for Dementia Assessment ${ }^{164}$ (STIDA). Research staff is trained in the administration based on the Washington University protocol ${ }^{159}$. 


\section{Diagnostic endpoints}

Diagnosis of $\mathrm{MCl}$ and dementia are established by a review of all available clinical information (i.e., neuropsychological, medical, neurological, and functional but not including radiological data). A consensus group of expert diagnosticians review available data to assign a research diagnosis. Diagnosis of $\mathrm{MCl}$ is based on Petersen criteria as it has been adapted and validated for this diverse, community-based setting ${ }^{94,97}$. Diagnosis of all-cause dementia is based on standard criteria ${ }^{2}$ and dementia subtype is based on research criteria for $A D^{2}$, Lewy body dementia ${ }^{165}$, vascular dementia ${ }^{166}$, etc.

\section{Structural MRI}

A subset of participants undergoes brain MRI acquisition on a Siemens 3 Tesla scanner. The MRI protocol acquires data in a single 1.25 hour session that has been generally tolerated well. Table 3 displays the MRI acquisition protocol used in Offspring for primary imaging outcome measures and those that are part of ancillary or secondary efforts.

Table 3. MRI sequences proposed for the current study. Primary MRI outcomes will be derived with the first three sequences. Sequences shaded in grey are collected as part of ancillary or exploratory studies.

\begin{tabular}{|c|c|c|c|c|c|c|}
\hline $\begin{array}{l}\text { Sequenc } \\
\mathrm{e}\end{array}$ & $\begin{array}{l}\text { TE/TR } \\
\text { (ms) }\end{array}$ & $\begin{array}{l}\text { Voxel size } \\
(\mathrm{mm})\end{array}$ & $\begin{array}{l}\text { Flip angle } \\
\text { (degrees) }\end{array}$ & $\begin{array}{l}\text { Acquisition } \\
\text { time }\end{array}$ & $\begin{array}{l}\begin{array}{l}\text { Resolution } \\
\left(m^{\wedge} 3\right)\end{array} \\
\end{array}$ & $\begin{array}{l}\text { Slice thickness } \\
\text { (mm) }\end{array}$ \\
\hline 3DT1 & $2.26 / 2300$ & $1 \times 1 \times 1$ & 8 & $5: 21$ & $192 \times 256 \times 256$ & 1 \\
\hline FLAIR & $387 / 5000$ & $.4 \times .4 \times .9$ & $\mathrm{n} / \mathrm{a}$ & $5: 42$ & $192 \times 512 \times 512$ & 0.9 \\
\hline SWI & $20 / 27$ & $.9 \times .9 \times 1.5$ & 15 & $6: 13$ & $104 \times 232 \times 256$ & 1.5 \\
\hline DTI & $70 / 5500$ & $2 \times 2 \times 2$ & $\mathrm{n} / \mathrm{a}$ & $7: 16$ & $51 \times 114 \times 114$ & 2 \\
\hline MRS & $20 / 200$ & $30 \times 20 \times 20$ & 90 & $4: 26$ & $\mathrm{n} / \mathrm{a}$ & $\mathrm{n} / \mathrm{a}$ \\
\hline T2 TSE & $74 / 6650$ & $.4 \times .4 \times 2$ & $\mathrm{n} / \mathrm{a}$ & $6: 47$ & $448 \times 448 \times 41$ & 2 \\
\hline ASL & $\begin{array}{l}13.36 / 460 \\
0\end{array}$ & $1.9 \times 1.9 \times 4$ & $\mathrm{n} / \mathrm{a}$ & $5: 36$ & $36 \times 128 \times 128$ & 4 \\
\hline MRA & $3.42 / 21$ & $.3 \times .3 \times .5$ & 18 & $5: 33$ & $136 \times 696 \times 768$ & 0.5 \\
\hline $\begin{array}{l}\text { Resting } \\
\text { State }\end{array}$ & $30 / 2040$ & $2 \times 2 \times 3$ & 90 & $10: 24$ & $37 \times 94 \times 94$ & 3 \\
\hline
\end{tabular}

Primary neuroimaging outcome variables include regional volumetry and cortical thickness; regional white matter hyperintensity volume; presence, number, and region of cerebral 
microbleeds; and number and distribution of infarcts. Regional cortical thickness/volumetry. Measures of regional brain volume and cortical thickness are derived with FreeSurfer (http://surfer.nmr.mgh.harvard.edu/). We also derive regional diffusion metrics, metabolite concentrations, regional blood flow, resting state connectivity, hippocampal subfield anatomy, perivascular spaces, and large vessel morphology.

\section{PET Scanning}

A subset of 150 offspring participants undergoes amyloid and tau PET scans (within 4 months of each other) on a Siemens Biograph MCT PET scanner. This subset must also be willing and eligible for MRI. As with the MRI, our staff will be available throughout the PET scan procedure to provide support, reduce anxiety, optimize the comfort of the subject and remove the subject from the machine if requested.

First, an intravenous (IV) catheter is placed, followed by slow bolus injection (over 10-20 sec) of ${ }^{18} \mathrm{~F}$-Florbetaben (fibrillar amyloid- $\beta$ plaques) or ${ }^{18} \mathrm{~F}$-MK6240 (hyperphosphorylated tau in paired helical filaments). The amyloid scans are acquired in 5-minute frames from 50-70 minutes post-injection, while the tau scans are acquired in 5-minute frames from 80-110 minutes postinjection in order to reach pseudo-equilibrium. A low-dose CT scan is also acquired in the Siemens Biograph mCT PET scanner at the time of each PET scan for attenuation correction of annihilation photons. PET data are also corrected for radioactive decay, scanner normalization, detector deadtime, and random or scatter events.

T1-weighted brain MRIs are used for anatomical localization of the amyloid and tau PET signal. Briefly, dynamic PET frames are aligned to the crude mean of all frames. The structural T1 in FreeSurfer space is co-registered to the participant's mean PET image. PET data are quantified 
as the standard uptake value ratio (SUVR), using PET data at pseudo-equilibrium for each radiotracer and an inferior cerebellar gray matter reference region (derived from FreeSurfer).

Analyses for amyloid includes regions involved in Thal phasing of amyloid plaque deposition at autopsy in cases with $\mathrm{AD}$ (citation). A visual rating method similar to that of Barthel and colleagues ${ }^{167}$ is used for the visual classification of amyloid- $\beta$ deposition as amyloid negative or amyloid positive. Analyses for tau includes regions involved in Braak staging of neurofibrillary tangle deposition at autopsy in cases with AD.

\section{Follow-up}

Longitudinal follow-up of this offspring cohort will be important to further illuminate mechanisms of disparities. From the Dominantly Inherited Alzheimer Network ${ }^{39}$ (DIAN) study in which the parental age of dementia onset can be used to reliably predict the offspring age of dementia onset, hippocampal volume changes do not begin until approximately 15 years prior to dementia, while memory changes do not begin until approximately 5-10 years prior to dementia. Given that dementia onset due to AD occurs in late life $(4 \%<65$ years old, $16 \% 65-74$ years old, $44 \% 75-84$ years old, $37 \%>85$ years old $)^{168}$, we can expect to observe changes in amyloid and tau, which begin decades prior to dementia onset, but not changes in neurodegeneration or cognition. As a result, the recruitment plan was structured so that there will be sufficient sample size and power for a 5-year follow-up, taking conservative estimates of attrition into account.

\section{DISCUSSION}

There is a critical need to identify people at risk for developing AD before they are symptomatic, or at the preclinical phase. There have been several groundbreaking studies, such 
as the Wisconsin Registry for Alzheimer's Prevention, Adult Children Study, BIOCARD, and Framingham, that have identified cognitive and other markers among asymptomatic people at higher familial risk for AD. The Offspring Study is unique due to its enrollment of large numbers of middle-aged Latinx and African American offspring of educationally and racially/ethnically diverse parents, allowing for increased knowledge about groups who are at higher risk for cognitive decline and racial differences in etiologic pathways to AD. WHICAP parents have been diagnosed detailed in-person assessment, longitudinal cognitive data, risk factors, and date of onset, and most with dementia were incident cases during the course of their follow-up, allowing for more precise age-at-onset dates and risk factor information collected prior to dementia onset. Mechanisms of disparities are difficult to study if samples are limited to age 65 and older because several factors attenuate the relationships of these risk factors with AD when measured in old age. Our group found that racial disparities in cognitive function narrow with age due to selective survival. In addition, there is increasing evidence for the importance of cardiovascular and cerebrovascular risk factors for $A D$, but these relationships appear to be strongest when cardiovascular factors are measured in middle age. The stronger association between mid-life risk factors and later life $A D$ may be because $A D$ pathology begins in the brain decades before the onset of clinical symptoms. This is particularly relevant for studying racial disparities in $A D$ because cardiovascular risk factors are more prevalent and have an earlier age of onset among minorities, in whom the potential influence of inflammatory, accelerated aging, and cardiovascular factors on the development of $A D$ may take place at an earlier age. 


\section{ACKNOWLEDGMENTS}

This research is supported by RF1 AG054070 and R01 AG058067 funded by the National Institute on Aging (NIA). We thank the Offspring study participants and the Offspring and WHICAP research and support staff for their contributions to this study. This publication was supported by the National Center for Advancing Translational Sciences, National Institutes of Health, through Grant Number UL1TR001873. The content is solely the responsibility of the authors and does not necessarily represent the official views of the NIH. 



\section{REFERENCES}

[1] Demirovic J, Prineas R, Loewenstein DA, Bean J, Duara R, Sevush S. Prevalence of dementia in three ethnic groups: The south Florida program on aging and health. Annals of Epidemiology. 2003;13(6):474-478.

2. Dilworth-Anderson P, Hendrie HC, Manly JJ, Khachaturian AS, Fazio S. Diagnosis and assessment of Alzheimer's disease in diverse populations. Alzheimer's \& Dementia. 2008;4(4):305-309.

3. Gurland BJ, Wilder DE, Lantingua R, Stern Y, Chen J. Rates of dementia in three ethnoracial groups. International Journal of Geriatric Psychiatry. 1999;14(6):481-493.

4. Haerer AF, Anderson DW, Schoenberg BS. Survey of major neurologic disorders in a biracial United States population: The Copiah COuntry Study. Southern Medical Journal. 1987;80:339343.

5. Harwood DG, Ownby RL. Ethnicity and dementia. Current Psychology Report. 2000;2(1):40-45.

6. Manly JJ, Mayeux R. Ethnic Differences in Dementia and Alzheimer's Disease. National Academies Press; 2004.

7. Perkins P, Annegers JF, Doody RS, Cooke N, Aday L, Vernon SW. Incidence and prevalence of dementia in a multiethnic cohort of municipal retirees. Neurology. 1997;49(1):44-50.

8. Steenland K, Goldstein FC, Levey A, Wharton W. A meta-analysis of Alzheimer's disease incidence and prevalence comparing African-Americans and caucasians. Journal of Alzheimer's Disease. 2015;50(1):71-76.

9. Tang $\mathrm{MX}$, Cross $\mathrm{P}$, Andrews $\mathrm{H}$, et al. Incidence of Alzheimer's disease in African-Americans, Caribbean Hisapnics and Caucasians in northern Manhattan. Neurology. 2001;56:49-56.

10. Whitmer RA. Ethnic and racial disparities in ten-year cumulative prevalence of dementia and alzheimer's disease. Alzheimer's \& Dementia. 2014;10(4):152.

11. Yaffe K, Falvey C, Harris TB, Newman A, Satterfield S, Koster A. Effect of socioeconomic disparities on incidence of dementia among biracial older adults: Prospective study. BMJ. 2013;347:7051.

12. Lines LM, Wiener JM. Racial and ethnic disparities in Alzheimer's Disease: A literature review. Office of disability, aging and long term care policy. 2014;1(1):1-25.

13. Mayeda ER, Glymour MM, Quesenberry CP, Whitmer RA. Inequalities in dementia incidence between six racial and ethnic groups over 14 years. Alzheimer's \& Dementia. 2016;12(3):216-224.

14. Mehta KM, Yeo GW. Systemic review of dementia prevalence and incidence in United States race/ethnic populations. Alzheimer's \& Dementia. 2017;13(1):72-83.

15. Matthews KA, Xu W, Gaglioti AH, et al. Racial and ethnic estimates of Alzheimer's disease and related dementias in the United States (2015-2060) in adults aged $\geq 65$ years. Alzheimer's \& Dementia. 2019;15(1):17-24. doi:10.1016/j.jalz.2018.06.3063 
16. Adelman S, Blanchard M, Livingston $\mathrm{G}$. A systematic review of the prevalence and covariates of dementia or relative cognitive impairment in the older African-Caribbean population in Britain. International Journal of Geriatric Psychiatry. 2009;24(7):657-665. doi:10.1002/gps.2186

17. Adelman S, Blanchard M, Rait G, Leavey G, Livingston G. Prevalence of dementia in AfricanCaribbean compared with UK-born White older people: two-stage cross-sectional study. Br J Psychiatry. 2011;199(2):119-125. doi:10.1192/bjp.bp.110.086405

18. Barnes LL, Wilson RS, Li Y, et al. Racial Differences in the Progression of Cognitive Decline in Alzheimer Disease. The American Journal of Geriatric Psychiatry. 2005;13(11):959-967. doi:10.1097/00019442-200511000-00006

19. Lee HB, Richardson AK, Black BS, Shore AD, Kasper JD, Rabins PV. Race and Cognitive Decline among Community-dwelling Elders with Mild Cognitive Impairment: Findings from the Memory and Medical Care Study. Aging Ment Health. 2012;16(3):372-377. doi:10.1080/13607863.2011.609533

20. Sachs-Ericsson N, Blazer DG. Racial Differences in Cognitive Decline in a Sample of CommunityDwelling Older Adults: The Mediating Role of Education and Literacy. The American Journal of Geriatric Psychiatry. 2005;13(11):968-975. doi:10.1097/00019442-200511000-00007

21. Alves de Moraes S, Szklo M, Knopman D, Sato R. The Relationship between Temporal Changes in Blood Pressure and Changes in Cognitive Function: Atherosclerosis Risk in Communities (ARIC) Study. Preventive Medicine. 2002;35(3):258-263. doi:10.1006/pmed.2002.1077

22. Anstey K, Christensen $\mathrm{H}$. Education, activity, health, blood pressure and apolipoprotein $\mathrm{E}$ as predictors of cognitive change in old age: a review. Gerontology. 2000;46(3):163-177. doi:10.1159/000022153

23. Breteler MMB. Vascular risk factors for Alzheimer's disease:: An epidemiologic perspective. Neurobiology of Aging. 2000;21(2):153-160. doi:10.1016/S0197-4580(99)00110-4

24. Cukierman T, Gerstein HC, Williamson JD. Cognitive decline and dementia in diabetessystematic overview of prospective observational studies. Diabetologia. 2005;48(12):2460-2469. doi:10.1007/s00125-005-0023-4

25. Elias MF, Robbins MA, Elias PK, Streeten DHP. A longitudinal study of blood pressure in relation to performance on the Wechsler Adult Intelligence Scale. Health Psychology. 19981201;17(6):486. doi:10.1037/0278-6133.17.6.486

26. Elias MF. Effects of chronic hypertension on cognitive functioning. Geriatrics (Basel). 1998;53 Suppl 1:S49-52.

27. Leibson CL, Rocca WA, Hanson VA, et al. Risk of Dementia among Persons with Diabetes Mellitus: A Population-based Cohort Study. American Journal of Epidemiology. 1997;145(4):301-308. doi:10.1093/oxfordjournals.aje.a009106

28. Luchsinger JA, Mayeux R. Cardiovascular risk factors and Alzheimer's disease. Curr Atheroscler Rep. 2004;6(4):261-266. doi:10.1007/s11883-004-0056-z 
29. Luchsinger J, Cheng D, Tang M, Schupf N, Mayeux R. Central obesity in the elderly is related to late onset Alzheimer's disease. Alzheimer Dis Assoc Disord. 2012;26(2):101-105.

doi:10.1097/WAD.0b013e318222f0d4

30. Luchsinger J, Reitz C, Honig MD LS, Tang M-X, Shea S, Mayeux R. Aggregation of Vascular Risk Factors and Risk of Incident Alzheimer's Disease. Neurology. 2005;65(4):545-551.

doi:10.1212/01.wnl.0000172914.08967.dc

31. Kivipelto $M$, Helkala E-L, Hanninen $T$, et al. Midlife vascular risk factors and late-life mild cognitive impairment: A population-based study. Neurology. 2001;56(12):1683-1689.

doi:10.1212/WNL.56.12.1683

32. Launer LJ, Ross GW, Petrovitch H, et al. Midlife blood pressure and dementia: the Honolulu-Asia

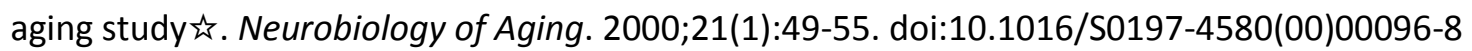

33. Antsey K, Christensen $\mathrm{H}$. Education, activity, health, blood pressure and apolipoprotein $\mathrm{E}$ as predictors of cognitive change in old age: a review. Gerontology. 2000;46:163-177.

34. Luchsinger J, Mayeux R. Cardiovascular risk factors and Alzheimer's disease. Curr Atheroscler Rep. 2004;6(4):261-266.

35. Leibson CL, Rocca WA, Hanson VA, et al. The risk of dementia among persons with diabetes mellitus: a population-based cohort study. Annals of the New York Academy of Sciences. 1997;826:422-427.

36. Luchsinger JA, Tang MX, Shea S, Mayeux R. Hyperinsulinemia and risk of Alzheimer disease. Neurology. 2004;63:1187-1192.

37. Noble JM, Schupf N, Manly JJ, Andrews H, Tang M-X, Mayeux R. Secular Trends in the Incidence of Dementia in a Multi-Ethnic Community. Journal of Alzheimer's Disease. 2017;60(3):1065-1075. doi:10.3233/JAD-170300

38. Vonk JMJ, Arce Rentería M, Avila JF, et al. Secular trends in cognitive trajectories of diverse older adults. Alzheimer's \& Dementia. 2019;15(12):1576-1587. doi:10.1016/j.jalz.2019.06.4944

39. Bateman RJ, Xiong C, Benzinger TLS, et al. Clinical and Biomarker Changes in Dominantly Inherited Alzheimer's Disease. New England Journal of Medicine. 2012;367(9):795-804.

doi:10.1056/NEJMoa1202753

40. Murray J, Tsui WH, Li Y, et al. FDG and Amyloid PET in Cognitively Normal Individuals at Risk for Late-Onset Alzheimer's Disease. Adv J Mol Imaging. 2014;4(2):15-26.

doi:10.4236/ami.2014.42003

41. Sperling R, Mormino E, Johnson K. The evolution of preclinical Alzheimer's disease: implications for prevention trials. Neuron. 2014;84(3):608-622. doi:10.1016/j.neuron.2014.10.038

42. Gottesman RF, Albert MS, Alonso A, et al. Associations Between Midlife Vascular Risk Factors and 25-Year Incident Dementia in the Atherosclerosis Risk in Communities (ARIC) Cohort. JAMA Neurology. 2017;74(10):1246-1254. doi:10.1001/jamaneurol.2017.1658 
43. Walker KA, Gottesman RF, Wu A, et al. Systemic inflammation during midlife and cognitive change over 20 years: The ARIC Study. Neurology. 2019;92(11):e1256-e1267. doi:10.1212/WNL.0000000000007094

44. Walker KA, Windham BG, Power MC, et al. The association of mid-to late-life systemic inflammation with white matter structure in older adults: The Atherosclerosis Risk in Communities Study. Neurobiology of Aging. 2018;68:26-33.

doi:10.1016/j.neurobiolaging.2018.03.031

45. Walker Keenan A., Power Melinda C., Hoogeveen Ron C., et al. Midlife Systemic Inflammation, Late-Life White Matter Integrity, and Cerebral Small Vessel Disease. Stroke. 2017;48(12):31963202. doi:10.1161/STROKEAHA.117.018675

46. Gustafson D, Rothenberg E, Blennow K, Steen B, Skoog I. An 18-Year Follow-up of Overweight and Risk of Alzheimer Disease. Arch Intern Med. 2003;163(13):1524-1528.

doi:10.1001/archinte.163.13.1524

47. Logroscino G, Kang JH, Grodstein F. Prospective study of type 2 diabetes and cognitive decline in women aged 70-81 years. BMJ. 2004;328(7439):548. doi:10.1136/bmj.37977.495729.EE

48. Forrester S, Jacobs D, Zmora R, Schreiner P, Roger V, Kiefe Cl. Racial differences in weathering and its associations with psychosocial stress: The CARDIA study. SSM - Population Health. 2019;7:100319. doi:10.1016/j.ssmph.2018.11.003

49. Geronimus AT, Hicken MT, Pearson JA, Seashols SJ, Brown KL, Cruz TD. Do US Black Women Experience Stress-Related Accelerated Biological Aging? Human Nature. 2010;21(1):19-38. doi:10.1007/s12110-010-9078-0

50. Levine ME, Crimmins EM. Evidence of accelerated aging among African Americans and its implications for mortality. Soc Sci Med. 2014;118:27-32. doi:10.1016/j.socscimed.2014.07.022

51. Zahodne LB, Manly JJ, Azar M, Brickman AM, Glymour MM. Racial Disparities in Cognitive Performance in Mid- and Late Adulthood: Analyses of Two Cohort Studies. J Am Geriatr Soc. 2016;64(5):959-964. doi:10.1111/jgs.14113

52. Yao L, Robert SA. Examining the Racial Crossover in Mortality between African American and White Older Adults: A Multilevel Survival Analysis of Race, Individual Socioeconomic Status, and Neighborhood Socioeconomic Context. J Aging Res. 2011;2011:132073-132073. doi:10.4061/2011/132073

53. Goldman N, Glei DA, Weinstein M. The Best Predictors of Survival: Do They Vary by Age, Sex, and Race? Population and development review. 2017;43(3):541-560. doi:10.1111/padr.12079

54. Cupples LA, Farrer LA, Sadovnick AD, Relkin N, Whitehouse P, Green RC. Estimating risk curves for first-degree relatives of patients with Alzheimer's disease: The REVEAL study. Genetics in Medicine. 2004;6(4):192-196. doi:10.1097/01.GIM.0000132679.92238.58 
55. Silverman JM, Ciresi G, Smith CJ, Marin DB, Schnaider-Beeri M. Variability of Familial Risk of Alzheimer Disease Across the Late Life Span. Arch Gen Psychiatry. 2005;62(5):565-573. doi:10.1001/archpsyc.62.5.565

56. Cannon-Albright LA, Foster NL, Schliep K, et al. Relative risk for Alzheimer disease based on complete family history. Neurology. 2019;92(15):e1745-e1753. doi:10.1212/WNL.0000000000007231

57. Mosconi L, Berti V, Swerdlow RH, Pupi A, Duara R, de Leon M. Maternal transmission of Alzheimer's disease: Prodromal metabolic phenotype and the search for genes. Human Genomics. 2010;4(3):170. doi:10.1186/1479-7364-4-3-170

58. Bendlin BB, Carlsson CM, Gleason CE, et al. Midlife predictors of Alzheimer's disease. Maturitas. 2010;65(2):131-137. doi:10.1016/j.maturitas.2009.12.014

59. Snowden JS, Stopford CL, Julien CL, et al. Cognitive phenotypes in Alzheimer's disease and genetic risk. Cortex. 2007;43(7):835-845. doi:10.1016/s0010-9452(08)70683-x

60. Mosconi L, Tsui W, Murray J, et al. Maternal age affects brain metabolism in adult children of mothers affected by Alzheimer's disease. Neurobiology of Aging. 2012;33(3):624.e1-624.e9. doi:10.1016/j.neurobiolaging.2011.03.003

61. Johnson SC, Schmitz TW, Trivedi MA, et al. The Influence of Alzheimer Disease Family History and Apolipoprotein E \{varepsilon\}4 on Mesial Temporal Lobe Activation. J Neurosci. 2006;26(22):6069-6076. doi:10.1523/jneurosci.0959-06.2006

62. Honea RA, Swerdlow RH, Vidoni ED, Goodwin J, Burns JM. Reduced gray matter volume in normal adults with a maternal family history of Alzheimer disease. Neurology. 2010;74(2):113-120. doi:10.1212/WNL.0b013e3181c918cb

63. Honea RA, Vidoni ED, Swerdlow RH, Burns JM. Maternal family history is associated with Alzheimer's disease biomarkers. J Alzheimers Dis. 2012;31(3):659-668. doi:10.3233/JAD-2012120676

64. Day GS, Cruchaga C, Wingo T, Schindler SE, Coble D, Morris JC. Association of Acquired and Heritable Factors With Intergenerational Differences in Age at Symptomatic Onset of Alzheimer Disease Between Offspring and Parents With Dementia. JAMA Netw Open. 2019;2(10):e1913491e1913491. doi:10.1001/jamanetworkopen.2019.13491

65. Stamm BC, Lao PJ, Rizvi B, et al. Parental History of Dementia Is Associated with Increased Small Vessel Cerebrovascular Disease. J Gerontol A Biol Sci Med Sci. doi:10.1093/gerona/glz291

66. Bendlin BB, Ries ML, Canu E, et al. White matter is altered with parental family history of Alzheimer's disease. Alzheimer's \& Dementia: The Journal of the Alzheimer's Association. 2010;6(5):394-403. doi:10.1016/j.jalz.2009.11.003

67. Donix M, Ercoli LM, Siddarth $\mathrm{P}$, et al. Influence of Alzheimer disease family history and genetic risk on cognitive performance in healthy middle-aged and older people. The American Journal of Geriatric Psychiatry. 2012;20(7):565-573. doi:10.1097/JGP.0b013e3182107e6a 
68. Mistur R, Mosconi L, Santi SD, et al. Current Challenges for the Early Detection of Alzheimer's Disease: Brain Imaging and CSF Studies. Journal of Clinical Neurology. 2009;5(4):153-166. doi:10.3988/jcn.2009.5.4.153

69. Green RC, Cupples LA, Go R, et al. Risk of dementia among white and African American relatives of patients with Alzheimer disease. Jama. 2002;287(3):329-336.

70. Albert M, Soldan A, Gottesman R, et al. Cognitive changes preceding clinical symptom onset of mild cognitive impairment and relationship to ApoE genotype. Current Alzheimer Research. 2014;11(8):773-784.

71. Hom J, Turner MB, Risser R, Bonte FJ, Tintner R. Cognitive deficits in asymptomatic first-degree relatives of Alzheimer's disease patients. J Clin Exp Neuropsychol. 1994;16(4):568-576. doi:10.1080/01688639408402668

72. Debette $\mathrm{S}$, Wolf PA, Beiser A, et al. Association of parental dementia with cognitive and brain MRI measures in middle-aged adults. Neurology. 2009;73(24):2071-2078. doi:10.1212/WNL.0b013e3181c67833

73. Miller MI, Younes L, Ratnanather JT, et al. The diffeomorphometry of temporal lobe structures in preclinical Alzheimer's disease. Neuroimage Clin. 2013;3:352-360. doi:10.1016/j.nicl.2013.09.001

74. Mosconi L, Mistur R, Switalski R, et al. Declining brain glucose metabolism in normal individuals with a maternal history of Alzheimer disease. Neurology. 2009;72(6):513-520.

doi:10.1212/01.wnl.0000333247.51383.43

75. Okonkwo OC, Xu G, Dowling NM, et al. Family history of Alzheimer disease predicts hippocampal atrophy in healthy middle-aged adults. Neurology. 2012;78(22):1769-1776. doi:10.1212/WNL.0b013e3182583047

76. Reiter K, Alpert KI, Cobia DJ, et al. COGNITIVELY NORMAL INDIVIDUALS WITH AD PARENTS MAY BE AT RISK FOR DEVELOPING AGING-RELATED CORTICAL THINNING PATTERNS CHARACTERISTIC OF AD. Neuroimage. 2012;61(3):525-532. doi:10.1016/j.neuroimage.2012.03.083

77. Xu G, Mclaren DG, Ries ML, et al. The influence of parental history of Alzheimer's disease and apolipoprotein E $\varepsilon 4$ on the BOLD signal during recognition memory. Brain. 2009;132(2):383-391. doi:10.1093/brain/awn254

78. Johnson SC, Schmitz TW, Trivedi MA, et al. The Influence of Alzheimer Disease Family History and Apolipoprotein E $\varepsilon 4$ on Mesial Temporal Lobe Activation. J Neurosci. 2006;26(22):6069-6076. doi:10.1523/JNEUROSCI.0959-06.2006

79. Mosconi L, Tsui W, Murray J, et al. Maternal age affects brain metabolism in adult children of mothers affected by Alzheimer's disease. Neurobiol Aging. 2012;33(3):624.e1-624.e9. doi:10.1016/j.neurobiolaging.2011.03.003

80. Ercoli L, Siddarth P, Harrison T, Jimenez E, Jarvik LF. Similar Neurocognitive Performance of Adults With and Without a History of Parental Alzheimer's Disease: A Pilot Study. J Geriatr Psychiatry Neurol. 2005;18(4):208-212. doi:10.1177/0891988705281866 
81. Jarvik LF, La Rue A, Gokhman I, et al. Middle-Aged Children of Alzheimer Parents, A Pilot Study: Stable Neurocognitive Performance at 20-Year Follow-up. J Geriatr Psychiatry Neurol. 2005;18(4):187-191. doi:10.1177/0891988705281862

82. Sager MA, Hermann B, La Rue A. Middle-Aged Children of Persons With Alzheimer's Disease: APOE Genotypes and Cognitive Function in the Wisconsin Registry for Alzheimer's Prevention. J Geriatr Psychiatry Neurol. 2005;18(4):245-249. doi:10.1177/0891988705281882

83. Coats M, Morris JC. Antecedent Biomarkers of Alzheimer's Disease: The Adult Children Study. J Geriatr Psychiatry Neurol. 2005;18(4):242-244. doi:10.1177/0891988705281881

84. Sager MA, Hermann B, La Rue A. Middle-Aged Children of Persons With Alzheimer's Disease: APOE Genotypes and Cognitive Function in the Wisconsin Registry for Alzheimer's Prevention. J Geriatr Psychiatry Neurol. 2005;18(4):245-249. doi:10.1177/0891988705281882

85. Martinez-Miller EE, Prather AA, Robinson WR, et al. US acculturation and poor sleep among an intergenerational cohort of adult Latinos in Sacramento, California. Sleep. 2019;42(3). doi:10.1093/sleep/zsy246

86. Reitz C, Brayne C, Mayeux R. Epidemiology of Alzheimer disease. Nat Rev Neurol. 2011;7(3):137152. doi:10.1038/nrneurol.2011.2

87. Kapasi A, DeCarli C, Schneider JA. Impact of Multiple Pathologies on the Threshold for Clinically Overt Dementia. Acta Neuropathol. 2017;134(2):171-186. doi:10.1007/s00401-017-1717-7

88. Jack CR, Bennett DA, Blennow K, et al. NIA-AA Research Framework: Towards a Biological Definition of Alzheimer's Disease. Published 2017. https://www.alz.org/aaic/_downloads/draftnia-aa-9-19-17.pdf

89. Gottesman RF, Albert MS, Alonso A, et al. Associations Between Midlife Vascular Risk Factors and 25-Year Incident Dementia in the Atherosclerosis Risk in Communities (ARIC) Cohort. JAMA Neurol. 2017;74(10):1246-1254. doi:10.1001/jamaneurol.2017.1658

90. Kaplan JB, Bennett T. Use of Race and Ethnicity in Biomedical Publication. JAMA. 2003;289(20):2709-2716. doi:10.1001/jama.289.20.2709

91. Boyd RW, Lindo EG, Weeks LD, McLemore MR. On Racism: A New Standard For Publishing On Racial Health Inequities. Health Affairs Blog. Accessed August 8, 2020. https://www.healthaffairs.org/do/10.1377/hblog20200630.939347/full/

92. Hill CV, Pérez-Stable EJ, Anderson NA, Bernard MA. The National Institute on Aging Health Disparities Research Framework. Ethn Dis. 25(3):245-254. doi:10.18865/ed.25.3.245

93. Tang MX, Stern Y, Marder K, et al. The APOE-epsilon4 allele and the risk of Alzheimer disease among African Americans, whites, and Hispanics. JAMA : the journal of the American Medical Association. 1998;279(10):751-755. 
94. Manly JJ, Bell-McGinty S, Tang M-X, Schupf N, Stern Y, Mayeux R. Implementing Diagnostic Criteria and Estimating Frequency of Mild Cognitive Impairment in an Urban Community. Arch Neurol. 2005;62(11):1739-1746. doi:10.1001/archneur.62.11.1739

95. McKhann GM, Knopman DS, Chertkow H, et al. The diagnosis of dementia due to Alzheimer's disease: Recommendations from the National Institute on Aging-Alzheimer's Association workgroups on diagnostic guidelines for Alzheimer's disease. Alzheimer's \& dementia : the journal of the Alzheimer's Association. 2011;7(3):263-269.

96. Petersen RC, Smith GE, Waring SC, Ivnik RJ, Tangalos EG, Kokmen E. Mild Cognitive Impairment: Clinical Characterization and Outcome. Arch Neurol. 1999;56(3):303-308. doi:10.1001/archneur.56.3.303

97. Manly JJ, Tang M-X, Schupf N, Stern Y, Vonsattel J-PG, Mayeux R. Frequency and course of mild cognitive impairment in a multiethnic community. Ann Neurol. 2008;63(4):494-506. doi:10.1002/ana.21326

98. Barnes LL, Bennett DA. Alzheimer's Disease In African Americans: Risk Factors And Challenges For The Future. Health Affairs. 2014;33(4):580-586. doi:10.1377/hlthaff.2013.1353

99. Ramirez AH, Sulieman L, Schlueter DJ, et al. The All of Us Research Program: data quality, utility, and diversity. medRxiv. Published online June 3, 2020:2020.05.29.20116905. doi:10.1101/2020.05.29.20116905

100. United States Office of Education. Biennial Survey of Education in the United States. U.S. Govt. Print. Off; 1916. //catalog.hathitrust.org/Record/007406671

101. Jones TJ. Negro Education: A Study of Private and Higher Schools for Colored People in the United States. United States Office of Education, Bulletin, 1916, Vols. 1(No. 38) and 2 (No. 39). United States Government Printing Office; -32676.

102. Blose D, Caliver A. Statistics of the Education of Negroes, 1929-30 and 1931-32. United States Office of Education, Bulletin No. 13. United States Government Printing Office; -32676.

103. Blose D, Caliver A. Statistics of the Education of Negroes, 1933-34 and 1935-36. United States Office of Education, Bulletin No. 13. United States Government Printing Office; -32676.

104. Margo RA. Disenfranchisement, School Finance, and the Economics of Segregated Schools in the United States South, 1980-1910. Garland Publishing; 1985.

105. Margo RA. Race and Schooling in the South, 1880-1950: An Economic History. University of Chicago Press, 5801 South Ellis, Chicago, IL 60637 (paperback: ISBN-0-226-50511-1; clothbound: ISBN-0-226-50510-3).; 1990.

106. Anderson JD. The Education of Blacks in the South, 1860-1935. University of North Carolina Press; 1988.

107. Schupf N, Kapell D, Nightingale B, et al. Specificity of the fivefold increase in AD in mothers of adults with Down syndrome. Neurology. 2001;57(6):979-984. 
108. Adler NE, Epel ES, Castellazzo G, Ickovics JR. Relationship of subjective and objective social status with psychological and physiological functioning: preliminary data in healthy white women. Health Psychol. 2000;19(6):586-592. doi:10.1037//0278-6133.19.6.586

109. Mayer SE, Jencks C. Poverty and the distribution of material hardship. Journal of Human Resources. 1989;24:88-113.

110. Bureau of Labor Statistics. Standard Occupational Classification. Published online 2018. https://www.bls.gov/soc/.

111. Occupational Information Network, U.S. Department of Labor/Employment and Training Administration. O*NET OnLine website. Published online 2018. .http://www.onetonline.org/

112. Powell WR, Buckingham WR, Larson JL, et al. Association of Neighborhood-Level Disadvantage With Alzheimer Disease Neuropathology. JAMA Network Open. 2020;3(6):e207559-e207559. doi:10.1001/jamanetworkopen.2020.7559

113. Bennett DA, Schneider JA, Tang Y, Arnold SE, Wilson RS. The effect of social networks on the relation between Alzheimer's disease pathology and level of cognitive function in old people: a longitudinal cohort study. The Lancet Neurology. 2006;5(5):406-412. doi:10.1016/S14744422(06)70417-3

114. Smith J, Ryan L, Fisher G, Sonnega A, Weir D. HRS Psychosocial and Lifestyle Questionnaire 20062016. Survey Research Center, Institute for Social Research, University of Michigan; 2017. https://hrs.isr.umich.edu/sites/default/files/biblio/HRS\%2020062016\%20SAQ\%20Documentation_07.06.17_0.pdf

115. Cutrona CE, Russell DW. The provisions of social relationships and adaptation to stress. Advances in personal relationships. 1987;1(1):37-67.

116. Hughes ME, Waite LJ, Hawkley LC, Cacioppo JT. A Short Scale for Measuring Loneliness in Large Surveys. Res Aging. 2004;26(6):655-672. doi:10.1177/0164027504268574

117. Radloff LL. The CES-D: A self-report depression scale for research in the general population. Appl Psychol Meas. 1977;1:385-401.

118. American Psychiatric Association. DSM-5: Online Assessment measures. http://www.psychiatry.org/practice/dsm/dsm5/online-assessment-measures

119. Narrow WE, Clarke DE, Kuramoto SJ, et al. DSM-5 Field Trials in the United States and Canada, Part III: Development and Reliability Testing of a Cross-Cutting Symptom Assessment for DSM-5. AJP. 2013;170(1):71-82. doi:10.1176/appi.ajp.2012.12071000

120. Prenda KM, Lachman ME. Planning for the future: a life management strategy for increasing control and life satisfaction in adulthood. Psychol Aging. 2001;16(2):206-216.

121. Ryff CD, Singer B. Psychological well-being: meaning, measurement, and implications for psychotherapy research. Psychother Psychosom. 1996;65(1):14-23. doi:10.1159/000289026 
122. Rosenberg M. Society and the Adolescent Self-Image. Princeton University Press; 1965.

123. Lachman ME, Weaver SL. The sense of control as a moderator of social class differences in health and well-being. J Pers Soc Psychol. 1998;74(3):763-773. doi:10.1037//0022-3514.74.3.763

124. Williams DR, Yu Y, Jackson JS, Anderson NB. Racial Differences in Physical and Mental Health: Socio-economic Status, Stress and Discrimination. J Health Psychol. 1997;2(3):335-351. doi:10.1177/135910539700200305

125. Essed P. Knowledge and Resistance: Black Women Talk about Racism in the Netherlands and the USA. Feminism \& Psychology. 1991;1(2):201-219. doi:10.1177/0959353591012003

126. Barnes LL, De Leon CFM, Wilson RS, Bienias JL, Bennett DA, Evans DA. Racial Differences in Perceived Discrimination in a Community Population of Older Blacks and Whites. J Aging Health. 2004;16(3):315-337. doi:10.1177/0898264304264202

127. Brown C, Matthews KA, Bromberger JT, Chang Y. The Relation between Perceived Unfair Treatment and Blood Pressure in a Racially/Ethnically Diverse Sample of Women. American Journal of Epidemiology. 2006;164(3):257-262. doi:10.1093/aje/kwj196

128. Gee GC, Ryan A, Laflamme DJ, Holt J. Self-Reported Discrimination and Mental Health Status Among African Descendants, Mexican Americans, and Other Latinos in the New Hampshire REACH 2010 Initiative: The Added Dimension of Immigration. Am J Public Health. 2006;96(10):1821-1828. doi:10.2105/AJPH.2005.080085

129. Hunte HER, Williams DR. The Association Between Perceived Discrimination and Obesity in a Population-Based Multiracial and Multiethnic Adult Sample. Am J Public Health. 2009;99(7):12851292. doi:10.2105/AJPH.2007.128090

130. Taylor TR, Kamarck TW, Shiffman S. Validation of the Detroit area study discrimination scale in a community sample of older African American adults: The Pittsburgh healthy heart project. Int J Behav Med. 2004;11(2):88-94. doi:10.1207/s15327558ijbm1102_4

131. Clark R, Benkert RA, Flack JM. Large arterial elasticity varies as a function of gender and racismrelated vigilance in black youth. J Adolesc Health. 2006;39(4):562-569. doi:10.1016/j.jadohealth.2006.02.012

132. Acevedo A, Krueger KR, Navarro E, et al. The Spanish Translation and Adaptation of the Uniform Data Set of the National Institute on Aging Alzheimer's Disease Centers. Alzheimer Dis Assoc Disord. 2009;23(2):102-109. doi:10.1097/WAD.0b013e318193e376

133. Siedlecki KL, Manly JJ, Brickman AM, Schupf N, Tang M-X, Stern Y. Do neuropsychological tests have the same meaning in Spanish speakers as they do in English speakers? Neuropsychology. 2010;24(3):402-411. doi:10.1037/a0017515

134. Casaletto KB, Umlauf A, Marquine M, et al. Demographically Corrected Normative Standards for the Spanish Language Version of the NIH Toolbox Cognition Battery. J Int Neuropsychol Soc. 2016;22(3):364-374. doi:10.1017/S135561771500137X 
135. Buschke $H$, Fuld PA. Evaluating storage, retention, and retrieval in disordered memory and learning. Neurology. 1974;24:1019-1025.

136. Craft S, Newcomer J, Kanne S, et al. Memory improvement following induced hyperinsulinemia in Alzheimer's disease. Neurobiol Aging. 1996;17(1):123-130. doi:10.1016/0197-4580(95)02002-0

137. Possin KL, Laluz VR, Alcantar OZ, Miller BL, Kramer JH. Distinct Neuroanatomical Substrates and Cognitive Mechanisms of Figure Copy Performance in Alzheimer's Disease and Behavioral Variant Frontotemporal Dementia. Neuropsychologia. 2011;49(1):43-48.

doi:10.1016/j.neuropsychologia.2010.10.026

138. Gollan TH, Weissberger GH, Runnqvist E, Montoya RI, Cera CM. Self-ratings of Spoken Language Dominance: A Multi-Lingual Naming Test (MINT) and Preliminary Norms for Young and Aging Spanish-English Bilinguals. Biling (Camb Engl). 2012;15(3):594-615. doi:10.1017/S1366728911000332

139. Benton AL, Hamsher K. Multilingual Aphasia Examination. Published online 1983.

140. Goodglass H, Kaplan D. The Assessment of Aphasia and Related Disorders. 2nd ed. Lea and Febiger; 1983.

141. D'Elia LF, Satz P, Uchiyama CL, White T. Color Trails Test Professional Manual. Psychological Assessment Resources; 1994.

142. Wechsler D. Wechsler Adult Intelligence Scale-Revised. The Psychological Corporation; 1981.

143. Weintraub S, Dikmen SS, Heaton RK, et al. Cognition assessment using the NIH Toolbox. Neurology. 2013;80(11 Supplement 3):S54-S64. doi:10.1212/WNL.0b013e3182872ded

144. Gershon RC, Cook KF, Mungas D, et al. Language Measures of the NIH Toolbox Cognition Battery. Journal of the International Neuropsychological Society: JINS. Published online 2014:1-10.

145. Wilkinson GS, Robertson GJ. Wide Range Achievement Test--Fourth Edition.; 2006.

146. Del Ser T, González-Montalvo JI, Martínez-Espinosa S, Delgado-Villapalos C, Bermejo F. Estimation of premorbid intelligence in Spanish people with the Word Accentuation Test and its application to the diagnosis of dementia. Brain Cogn. 1997;33(3):343-356. doi:10.1006/brcg.1997.0877

147. Krueger KR, Lam CS, Wilson RS. The Word Accentuation Test - Chicago. J Clin Exp Neuropsychol. 2006;28(7):1201-1207. doi:10.1080/13803390500346603

148. Maj M, D'Elia L, Satz P, et al. Evaluation of two new neuropsychological tests designed to minimize cultural bias in the assessment of HIV-1 seropositive persons: A WHO study. Arch Clin Neuropsychol. 1993;8(2):123-135. doi:10.1093/arclin/8.2.123

149. Doty RL, Marcus A, William Lee W. Development of the 12 -item cross-cultural smell identification test (CC-SIT). The Laryngoscope. 1996;106(3):353-356. 
150. Louis ED, Lynch T, Marder K, Fahn S. Reliability of patient completion of the historical section of the Unified Parkinson's Disease Rating Scale. MovementDisorders. 1996;11:185-192.

151. Goetz CG, Stebbins GT, Chmura TA, Fahn S, Klawans HL, Marsden CD. Teaching tape for the motor section of the Unified Parkinson's disease rating scale. Mov Disord. 1995;10:263-266.

152. Richards M, Marder K, Cote L, Mayeux R. Interrater reliability of the Unified Parkinson's Disease Rating Scale motor examination. Movement Disorders. 1994;9:89-91.

153. World Health O. Recommendations on stroke prevention, diagnosis, and therapy. Report of the WHO Task Force on stroke and other cerebrovascular disorders. Stroke. 1989;20:1407-1431.

154. Buysse DJ, Reynolds CF, Monk TH, Berman SR, Kupfer DJ. The Pittsburgh sleep quality index: A new instrument for psychiatric practice and research. Psychiatry Research. 1989;28(2):193-213. doi:10.1016/0165-1781(89)90047-4

155. Radloff LS. The CES-D Scale: A Self-Report Depression Scale for Research in the General Population. Applied Psychological Measurement. 1977;1(3):385-401. doi:10.1177/014662167700100306

156. Gurland B, Kuriansky J, Sharpe L, Simon R, Stiller P, Birkett P. The Comprehensive assessment and Referral Evaluation (CARE)--rationale, development and reliability. International Journal of Aging and Human Development. 1977;8:9-42.

157. Golden RR, Teresi JA, Gurland BJ. Development of indicator scales for the Comprehensive Assessment and Referral Evaluation (CARE) interview schedule. Journal of Gerontology. 1984;39:138-146.

158. Teresi JA, Albert SM, Holmes D, Mayeux R. Use of Latent Class Analyses for the Estimation of Prevalence of Cognitive Impairment, and Signs of Stroke and Parkinson's Disease among AfricanAmerican Elderly of Central Harlem: Results of the Harlem Aging Project. NED. 1999;18(6):309321. doi:10.1159/000026226

159. Morris JC. The Clinical Dementia Rating (CDR): current version and scoring rules. Neurology. 1993;43(11):2412-2414.

160. Morris JC, Ernesto C, Schafer K, et al. Clinical dementia rating training and reliability in multicenter studies: the Alzheimer's Disease Cooperative Study experience. Neurology. 1997;48:1508-1510.

161. Farias ST. The measurement of everyday cognition (ECog): Scale development and psychometric properties. Neuropsychology. doi:10.1037/0894-4105.22.4.531

162. Filshtein $T$, Chan $M$, Mungas $D$, et al. Differential Item Functioning of the Everyday Cognition (ECog) Scales in Relation to Racial/Ethnic Groups. J Int Neuropsychol Soc. 2020;26(5):515-526. doi:10.1017/S1355617719001437 
163. Gilewski MJ, Zelinski EM, Schaie KW. The Memory Functioning Questionnaire for assessment of memory complaints in adulthood and old age. Psychol Aging. 1990;5(4):482-490.

doi:10.1037//0882-7974.5.4.482

164. Amariglio RE, Townsend MK, Grodstein F, Sperling RA, Rentz DM. Specific subjective memory complaints in older persons may indicate poor cognitive function. J Am Geriatr Soc.

2011;59(9):1612-1617. doi:10.1111/j.1532-5415.2011.03543.x

165. McKeith I, Dickson DW, Lowe J, et al. Diagnosis and management of dementia with Lewy bodies third report of the DLB consortium. Neurology. 2005;65(12):1863-1872.

166. Roman GC, Tatemichi TK, Erkinjuntti T, et al. Vascular dementia: diagnostic criteria for research studies. Report of the NINDS-AIREN International Workshop. Neurology. 1993;43:250-260.

167. Barthel H, Gertz H-J, Dresel S, et al. Cerebral amyloid- $\beta$ PET with florbetaben (18 F) in patients with Alzheimer's disease and healthy controls: a multicentre phase 2 diagnostic study. The Lancet Neurology. 2011;10(5):424-435.

168. Alzheimer's Association. 2017 Alzheimer's disease facts and figures. Alzheimer's \& Dementia. 2017;13(4):325-373. 
